\title{
Modelos in vitro para determinação da absorção de fármacos e previsão da relação dissolução/absorção
}

\author{
Jacqueline de Souza $^{1 *}$, Zaida Maria F. Freitas² ${ }^{2}$ Sílvia Storpirtis ${ }^{3}$ \\ ${ }^{1}$ Departamento de Farmácia, Escola de Farmácia, Universidade Federal de Ouro Preto, ${ }^{2}$ Departamento de \\ Medicamentos, Faculdade de Farmácia, Universidade Federal do Rio de Janeiro, ${ }^{3}$ Departamento de Farmácia, \\ Faculdade de Ciências Farmacêuticas, Universidade de São Paulo
}

*Correspondência:

J. Souza

Laboratório de Controle de Qualidade

Escola de Farmácia

Rua Costa Sena, 171 - Centro

35400000 - Ouro Preto - MG, Brasil

E. mail: jacsouza@ef.ufop.br
Fármacos contidos em formas farmacêuticas sólidas devem ter adequada solubilidade aquosa e permeabilidade intestinal para serem absorvidos após administração oral. A velocidade e a extensão com as quais um fármaco é absorvido podem variar devido às suas características físico-químicas e fatores relacionados à desintegração e dissolução. Segundo o Sistema de Classificação Biofarmacêutica (SCB), a dissolução e a permeação intestinal do fármaco podem limitar a absorção e, conseqüentemente, a ação terapêtica. Este trabalho objetiva discutir dados da literatura referentes à previsão da relação entre a dissolução de fármacos e sua absorção empregando sistemas in vitro. Para avaliar a permeação in vitro são discutidos modelos com tecidos e segmentos intestinais, vesículas extraídas de membranas e cultura de células. Na literatura existem estudos de permeabilidade utilizando células Caco-2, TC-7, 2/4/A1, MDCK e MDCK-MDR1. As células Caco-2 são extraídas de adenocarcinoma de cólon humano que, em cultura celular, se diferenciam em enterócitos, podendo ser acopladas a sistemas de dissolução. Estas técnicas representam importante ferramenta para estudos de dissolução/permeação, porém, ainda são limitadas e não conseguem reproduzir adequadamente os mecanismos de transporte ativo.

\section{INTRODUÇÃO}

Nas últimas décadas, têm-se estudado outras vias de administração de fármacos, mas a via oral ainda continua sendo preferencial. Isto ocorre devido à sua conveniência, baixo custo e maior aderência ao tratamento pelo paciente (Çelik, 1996; Manadas et al., 2002).

Os compostos para serem administrados oralmente devem ter adequada solubilidade aquosa e permeabilidade intestinal, de forma a atingir sua concentração terapêutica na circulação sistêmica (Çelik, 1996; Balimane et. al., 2000). A ineficácia clínica observada com o uso de alguns medicamentos, além de episódios de intoxicação, deram origem às investigações relacionadas à biodisponibilidade de produtos farmacêuticos (Storpirtis, Consiglieri, 1995; Dokoumetzidis, Macheras, 2006). Estudos mostraram que

\author{
- Fármaco/permeabilidade \\ - Fármaco/absorção oral \\ - Fármaco/dissolução \\ - Modelos in vitro \\ - Célula Caco-2
}


variações na formulação ou na técnica de fabricação podem gerar diferenças substanciais na absorção e, conseqüentemente, na resposta terapêutica dos fármacos (Rouge et al., 1996; Consiglieri, Storpirtis, 2000). Essas modificações podem ser monitoradas in vitro pelo perfil de dissolução, por meio da quantificação da fração de fármaco dissolvido e in vivo pela sua concentração plasmática, ambas em função do tempo. Os dados in vivo permitem determinar a biodisponibilidade do fármaco (Banakar, 1992; Ginski, Poli, 1999).

Atualmente, são realizados estudos de correlação in vitro/in vivo (CIVIV), que consistem na relação entre a propriedade biológica ou parâmetro derivado desta, produzido pela forma de dosagem e uma propriedade físico-química da mesma forma de dosagem (United, 2005). As perspectivas regulatórias das correlações obtidas entre os dados de dissolução in vitro e a biodisponibilidade in vivo de acordo com o guia para CIVIV do FDA (Food and Drug Administration) foram discutidas em 2001, por Uppoor. Para tal podem ser estabelecidos três níveis de correlação: C, que avalia um único ponto entre um parâmetro da dissolução e um parâmetro farmacocinético; $\mathbf{B}$, que se baseia no tempo médio de dissolução (TMD) in vitro comparado ao tempo médio de residência (TMR) ou ao TMD in vivo e A, que consiste em uma correlação ponto a ponto entre o perfil de dissolução in vitro e a fração absorvida in vivo. Esta última é obtida a partir da curva de concentração plasmática do fármaco em função do tempo. O estabelecimento de um modelo de correlação CIVIV, que atenda aos aspectos regulatórios, pode contribuir para a redução do número de estudos de bioequivalência utilizando voluntários humanos (Uppoor, 2001; Brasil, 2002).

Para estabelecer uma CIVIV é necessário conhecer as características físico-químicas dos fármacos, principalmente a solubilidade em líquidos biológicos e a permeabilidade. $\mathrm{O}$ Sistema de Classificação Biofarmacêutica (SCB) (Amidon et al., 1995) divide os fármacos em quatro grupos: I - altamente solúveis e altamente permeáveis (fosfato de cloroquina, cloridrato de biperideno, tartarato de ergotamina, etilestradiol, cloridrato de prometazina, cloridrato de propranolol); II pouco solúveis e altamente permeáveis (praziquantel, fenitoína, nifedipino, nevirapina, ibuprofeno); III - altamente solúveis e com baixa permeabilidade (hidroclorotiazida, ácido fólico, sulfato ferroso, fluconazol, captopril, amoxicilina, atenolol) e IV - fármacos pouco solúveis e pouco permeáveis (doxiciclina, dapsona, alopurinol, ácido nalidíxico). O SCB pode auxiliar na previsão da absorção in vivo e identificar se a biodisponibilidade de determinado produto farmacêutico é sensível a alterações do processo produtivo, dos constituintes da formulação ou da concentração do fármaco (Dressman et al., 1998; Kassin et al., 2003).

Para classificar um fármaco de acordo com o SCB devem-se realizar os estudos de dissolução in vitro cujo fundamento está descrito nos códigos oficiais farmacêuticos. $\mathrm{O}$ teste de dissolução determina a porcentagem da quantidade de princípio ativo, declarado no rótulo do produto, liberado no meio de dissolução, dentro do período de tempo especificado na monografia de cada produto, quando o mesmo é submetido à ação de aparelhagem específica, sob condições experimentais descritas (Farmacopéia, 1988). Para avaliar a fração do fármaco dissolvido em função do tempo podem ser traçados gráficos ou perfis de dissolução.

A determinação da permeabilidade dos fármacos através de membranas do trato gastrintestinal (TGI) contribui para prever sua biodisponiblidade. Existem vários modelos in vitro que possibilitam determinar a permeabilidade efetiva (Makhey et al., 1998; Luo et al., 2002; Mariappan et al., 2004). Os primeiros experimentos neste sentido utilizaram tecidos e segmentos de intestino de diferentes espécies animais. Foi observada significativa diferença morfológica e funcional entre os modelos animais e os enterócitos humanos. Devido a isto surgiram pesquisas e modelos matemáticos visando correlacionar os resultados de permeabilidade obtidos em animais com os originados em humanos. Atualmente, estão sendo estudadas metodologias empregando cultura de células como Caco-2, TC-7; 2/4/A1; MDCK e MDCK-MDR1 (Balimane et al., 2000; Putnam et al., 2002; Neulroff et al., 2005).

Este trabalho objetiva discutir dados da literatura referentes à previsão da relação entre a dissolução e a permeação de fármacos in vitro e sua absorção in vivo utilizando diferentes modelos experimentais.

\section{DISSOLUÇÃO}

Os testes de dissolução para formas farmacêuticas sólidas foram inicialmente incluídos na Farmacopéia Americana na década de 1960. Estes objetivam avaliar a cedência do fármaco contido ou não (dissolução intrínseca) em uma forma farmacêutica, para um meio similar aos líquidos corpóreos. O obstáculo mais significativo à aplicação universal dos métodos de dissolução foi a padronização das condições necessárias ao teste e que possibilitam a reprodução dos resultados por outros laboratórios. A partir desta constatação foram estudadas diferentes variáveis como: vibração durante o funcionamento do equipamento, alinhamento e velocidade do sistema de agitação, geometria da cuba de dissolução, adsorção, presença de gás dissolvido nos meios de dissolução, centralização dos cestos, posição/local de amostragem, entre outras. Os resultados desses trabalhos deram origem a um guia de dissolução publicado em 1978, nos Estados Unidos (Cox et al., 1978).

Os estudos de dissolução representam uma ferramenta indispensável para as várias etapas dos processos de desen- 
volvimento farmacotécnico de medicamentos, permitindo verificar a estabilidade dessas formulações. Na área de produção farmacêutica e controle de qualidade, os resultados do teste de dissolução podem ser empregados para detectar desvios de fabricação, para assegurar uniformidade durante a produção de um lote e reprodutibilidade lote a lote. Testes de dissolução também podem ser utilizados para avaliar mudanças após o registro do produto e podem auxiliar na decisão para a realização de estudos de bioequivalência e no desenvolvimento de CIVIV (Marques, 2002).

A modernização dos processos de produção farmacêutica e as pesquisas sobre diferentes formas de liberação de fármacos, como formas farmacêuticas sólidas de liberação prolongada e/ou retardada, têm suscitado o estudo de novas condições para realização do teste de dissolução. Isto tem ocasionado, também, maior ênfase no uso dos resultados in vitro para a previsão dos efeitos da terapêutica in vivo (Khan, 1996; Manadas et al., 2002).

O teste de dissolução, que era inicialmente indicado para fármacos com baixa solubilidade, vem sendo mais amplamente utilizado. Para realização do teste é necessário estabelecer condições, como: tipo de agitação, volume e características do meio de dissolução (de acordo com a solubilidade do fármaco e o local do TGI onde ocorre sua absorção) e valor de cedência do fármaco em função do objetivo terapêutico do medicamento. Para isto são consideradas as características físico-químicas da molécula e o poder discriminativo desejável para o teste. Os resultados obtidos devem possibilitar comparar a influência do processo produtivo e das variáveis da formulação com a adequada e completa liberação do fármaco em determinado tempo (Sathe et al., 1996; Manadas et al., 2002).

Os primeiros estudos de dissolução começaram a ser desenvolvidos há cerca de 100 anos, porém, foi a partir de 1950, com o reconhecimento da sua importância na biodisponibilidade de fármacos, que houve o crescimento no interesse por estes estudos (Dokoumetzidis, Macheras, 2006). Visando prever ou simular o comportamento in vivo de fármacos, foram desenvolvidos os gráficos de fração de fármaco dissolvido em função do tempo, também chamados de perfis de dissolução. Para melhor simular in vitro as condições in vivo é importante conhecer os fatores que podem retardar ou diminuir a dissolução e a permeação de fármacos, dentre os quais é possível citar: retenção do fármaco na forma farmacêutica; decomposição do mesmo pelos líquidos do TGI ou formação de complexos nãoabsorvíveis; ineficácia do transporte do fármaco através das membranas biológicas e metabolismo ou eliminação do mesmo antes de atingir a corrente sangüínea. Os dois primeiros fatores citados podem ser facilmente previstos por testes in vitro (Dressman et al., 1998).
A etapa limitante da absorção de fármacos pouco solúveis (classe II do SCB) é a dissolução in vivo, por isso é crescente o estudo de condições in vitro que reflitam ou controlem o processo de dissolução in vivo. Visando obter um método físico-químico que possibilite mimetizar a velocidade e a quantidade de fármaco dissolvido no TGI, além da ação de enzimas foi desenvolvido por Grundy e colaboradores (1997) um método de dissolução em duas fases. Eles objetivaram verificar a dissolução in vitro da formulação em uma fase aquosa composta de líquido intestinal simulado e a permeação através de membranas por meio da transferência do fármaco contido na fase aquosa para uma fase orgânica constituída de $n$-octanol. O modelo foi denominado sistema terapêutico gastrintestinal (GITS), sendo utilizado para avaliar partículas finamente divididas de nifedipino contidas em uma suspensão. O sistema possibilitou a liberação do fármaco por meio de uma bomba osmótica seguindo cinética de ordem zero. Os autores concluíram que o método de dissolução em duas fases produz valores semelhantes aos encontrados in vivo em relação à velocidade e extensão da absorção do nifedipino no TGI. Este método pode ser utilizado para avaliar outras formulações de fármacos pouco solúveis em água (Grundy et al., 1997).

O estabelecimento de uma correlação entre parâmetros inerentes ao fármaco, determinados in vitro, e as conseqüências de sua absorção determinadas in vivo, poderia minimizar custos no desenvolvimento e pesquisa de novas opções terapêuticas. Visando desenvolver modelos in vitro para prever a absorção destes novos fármacos, atualmente são realizadas pesquisas objetivando estimar a sua permeação através de membranas biológicas e criar modelos associando dissolução/permeação (Ginski, Polli, 1999). Foram descritos na literatura sistemas que mimetizam as mudanças fisiológicas e de $\mathrm{pH}$ do TGI. Para tal, o medicamento ou fármaco é adicionado, sob agitação, a um recipiente contendo meio líquido com $\mathrm{pH} 1$, sendo este acoplado a outro recipiente cujo $\mathrm{pH}$ do meio foi modifcado para 6 . O sistema contínuo é ligado a uma câmara contendo membrana formada de células de adenocarcinoma de cólon humano (Caco-2) visando determinar a permeabilidade do fármaco. Este sistema possibilita avaliar a dissolução e a permeação de fármacos solúveis em água, prevendo sua velocidade de absorção após administração oral em humanos. Ele possibilitou ainda, estimar a velocidade e a variabilidade da absorção de albendazol, que é um fármaco pouco solúvel (Kobayashi et al., 2001; He et al., 2003).

\section{ABSORÇÃO}

Os processos de absorção estão relacionados à permeação de compostos através de membranas biológicas 
sob influência das características físico-químicas de ambos. O transporte de fármacos para o interior da membrana intestinal é complexo e dinâmico. Ele inclui o transporte passivo, através dos enterócitos (transcelular), das junções entre os enterócitos (paracelular) e os mecanismos ativos, via transportadores (Balimane et al., 2000).

Dentre as principais famílias de transportadores de fármacos que promovem a absorção estão: os transportadores $\mathrm{ABC}$, compostos pelos grupos MDR, cujos substratos típicos são os compostos hidrofóbicos, agentes antitumorais, digoxina e imunossupressores, e MRP, cujos substratos típicos são conjugados aniônicos, agentes antitumorais, metotrexato e pravastatina. Existem também os transportadores peptídicos (PEPT) que são responsáveis pelo transporte de di e tripeptídeos e antibióticos $\beta$-lactâmicos; os transportadores de ácido monocarboxílico (MCT) que atuam na permeação de ácido lático e ácido salicílico; os transportadores de ânions orgânicos (OATP), cujo exemplo de substrato típico é a tiroxina, e de íons orgânicos (OAT, OCT e OCTN), cujos exemplos de substratos típicos são dopamina, metotrexato e cimetidina e os transportadores nucleosídeos (CNT e ENT), que atuam no transporte de nucleosídeos purínicos e pirimidínicos (Katsura, Inui, 2003).

Cabe ressaltar os transportadores de efluxo ou secreção, ou seja, aqueles que transportam os fármacos da membrana intestinal de volta para o lúmen. Estes transportadores funcionam como barreira à absorção. Os principais componentes desta classe são as glicoproteínas-P (Pgp), que são dependentes de ATP (170-180 KDa) e estão presentes em inúmeros órgãos e tecidos, incluindo cérebro, fígado, intestino, glândula adrenal, placenta, barreira hematoencefálica e rim (Katsura, Inui, 2003).

A absorção de substâncias é afetada por fatores fisiológicos relacionados ao TGI, características físico-químicas do fármaco e influência da forma farmacêutica e seus excipientes (Aulton, 1996; Macheras, Argyrakis, 1997).

Dentre os fatores fisiológicos podem-se ressaltar o tempo de esvaziamento gástrico e o trânsito intestinal das diversas formas farmacêuticas. O primeiro é mais lento em presença de alimento, sendo o segundo menos afetado pelas condições alimentares. A combinação entre os efeitos referentes ao maior tempo para ocorrer o esvaziamento gástrico e a potencial ligação entre os componentes alimentares e o fármaco pode diminuir sua absorção, principalmente para fármacos hidrossolúveis com alta biodisponibilidade. Fármacos pouco solúveis em água ou com solubilidade $\mathrm{pH}$ dependente são altamente afetados pelas mudanças pós-prandial do TGI podendo ter diferenças significativas na sua biodisponibilidade (Macheras, Argyrakis, 1997; Charman et al., 1997). As alterações de $\mathrm{pH}$, a área superficial de contato, a atividade enzimática, e a microflora presente também podem modificar a absorção de fármacos (Rouge et al., 1996).

A velocidade e a extensão da absorção de um fármaco podem ser alteradas devido à sua lipofilicidade, estado de ionização ou tamanho das partículas (Aungst, Shen, 1986; DeSesso, Jacobson, 2001). Fatores inerentes às formas farmacêuticas sólidas, administradas por via oral, como velocidade e extensão de desintegração e dissolução também são relevantes (Aulton, 1996).

\section{SÍTIOS DE ABSORÇÃO}

Os parâmetros anatômicos e fisiológicos do TGI afetam drasticamente a velocidade e a extensão da absorção de fármacos e nutrientes administrados por via oral.

A porção do TGI onde ocorre maior absorção é o duodeno e a parte proximal do jejuno. A mucosa onde este fenômeno ocorre consiste em um epitélio colunar simples, com uma membrana proeminente e vascular denominada lâmina própria. Para aumentar sua área superficial e, conseqüentemente, sua capacidade de promover absorção, esta mucosa possui pregas, depressões e microvilosidades. $\mathrm{O}$ epitélio formado não é uniforme, mas o principal tipo de células são os enterócitos. Estes se compõem de células epiteliais colunares, que são interligadas por estreitas junções. Existem numerosas microvilosidades na membrana celular apical das células epiteliais colunares, o que ocasiona aumento significativo da área superficial disponível para absorção e a aparência de borda em escova quando visualizadas ao microscópio (Pappenheimer, Reiss, 1987; DeSesso, Jacobson, 2001).

Fármacos ácidos são também absorvidos no estômago, pois nesta região, o pH ácido dificulta sua dissociação, promovendo sua difusão passiva pela porção lipofílica da bicamada da membrana. Fármacos básicos são absorvidos preferencialmente no intestino (Hirtz, 1984). O cólon também pode ser importante como sítio de absorção para alguns fármacos, como por exemplo, a teofilina (Rouge et al., 1996).

\section{MÉTODOS IN VITRO PARA DETERMINAÇÃO DA ABSORÇÃO DE FÁRMACOS}

A dissolução do fármaco e sua permeação intestinal podem representar fenômenos limitantes do processo de absorção, para formas farmacêuticas de uso oral (Polli et al., 1996). Existem vários estudos objetivando o desenvolvimento de modelos de correlação entre dados obtidos in vitro e o comportamento in vivo de fármacos (CIVIV) (Katori et al., 1995; Eddington et al., 1998; Balan et al., 2001; Rao et al., 2001). Estes estudos visam estabelecer 
correlações estatisticamente aceitáveis entre o processo de absorção do fármaco e sua liberação da forma farmacêutica determinada in vitro (Skelly et al., 1990; Cutler et al., 1997).

O grau de CIVIV depende da dissolução do fármaco, sua permeação intestinal e da fração da dose absorvida (Polli et al., 1996). A CIVIV apresenta grande relevância ética, pois minimiza os testes em voluntários sadios, podendo ser utilizada nos processos iniciais de aprovação do registro de novos medicamentos e/ou para isentar da repetição dos estudos de bioequivalência, produtos farmacêuticos que passaram por pequenas alterações pós-registro ou na sua escala de produção (GUIDANCE, 2002; Brasil, 2002).

Os métodos in vitro têm sido considerados adequados para mimetizar as características in vivo do epitélio intestinal. Eles são vastamente empregados no estudo de novos fármacos e permitem desvendar o mecanismo de absorção de moléculas em condições controladas. São usados, também, para avaliar a absorção de pró-fármacos e de aditivos farmacêuticos em uma formulação (Balimane et al., 2000).

A seguir serão abordados alguns modelos in vitro utilizados para determinação da absorção de fármacos administrados por via oral.

\section{Baseado em tecido animal}

Os modelos utilizando tecido animal para avaliar a permeabilidade intestinal são empregados desde 1950 (Balimane et al., 2000). Eles podem apresentar constituição semelhante às células do epitélio intestinal humano saudável, porém as diferenças observadas podem ter magnitudes diversas de acordo com a espécie (Atisook et al., 1990; Karasov et al., 1991; Laboisse et al., 1994; Asada et al., 1995). Werle e Hoffer (2006) utilizaram uma porção intestinal de íleo de cobaio, para avaliar a atividade da glicoproteína-P sobre a permeação da glutationa. O tecido foi contido em Câmara de permeabilidade dividida em duas porções sendo o experimento realizado utilizando solução salina tamponada ( $\mathrm{pH} 7,4)$, em atmosfera de $95 \% \mathrm{O}_{2}, 5 \%$ $\mathrm{CO}_{2}$ e temperatura de $37^{\circ} \mathrm{C}$. Os resultados consistiram no cálculo das permeabilidades aparentes da glutationa no sentido absortivo e secretório. Como controles do método experimental, foram utilizados terfenadina e verapamil, que são inibidores da Pgp e já possuem seus valores de permeabilidade aparente divulgados. O uso deste modelo possibilitou aos autores concluírem que a glutationa é um potente inibidor da Pgp.

Dentre os tecidos de intestino de animais utilizados, o de porco, além de ser de fácil aquisição e baixo custo, apresenta similaridades anatômicas e biológicas ao intestino humano. Este tem sido freqüentemente utilizado para estudos de mecanismos de transporte e metabolismo de fármacos (Hossain et al., 1990; Pietzonka et al., 2002). Uma restrição para a utilização deste modelo é a dificuldade em obter tecidos viáveis, ou que se mantenham adequados durante os experimentos, uma vez que necessitam de sangue e oxigenação constantes (Pietzonka et al., 2002).

Os modelos utilizando células de difusão são bastante descritos na avaliação da permeação cutânea. Estas células são compostas de dois compartimentos, sendo um contendo o líquido receptor e o outro a fase doadora, separados por uma membrana sintética ou pele. Sato e colaboradores (1991) descreveram a utilização da pele de orelha de porco como modelo animal para simular a pele humana. Eles estudaram a permeação do nicorandil, utilizado para prevenir e tratar angina. Os autores observaram que os resultados foram semelhantes utilizando a pele humana e a pele de orelha de porco. Isto pode ser devido a semelhança de espessura, aspecto morfológico e superfície lipídica entre os dois modelos.

\section{Intestino invertido}

O método utilizando porções invertidas do intestino consiste em avaliar a absorção por meio de segmentos de origem animal. Ele foi descrito inicialmente na década de 50 para estudar o transporte de açúcares e aminoácidos da porção mucosa para a parte serosa do intestino. Este modelo é ideal para o estudo de mecanismos de transporte de fármacos, assim como, absorção passiva, transporte ativo, além da cinética de transporte na presença e ausência de glicoproteínas-P (Balimane et al., 2000).

Essas porções intestinais são geralmente extraídas do intestino delgado de ratos e exigem cuidados durante a sua inversão, visando evitar danos morfológicos. Devido à ausência de sangue e nervos, estes tecidos apresentam reduzida viabilidade. Quando mantidos a $37^{\circ} \mathrm{C}$, em meios de cultura adequados, podem permanecer morfológica e metabolicamente ativos por cerca de 2 horas.

Galvão e colaboradores (1993) descreveram a utilização de um método de permeabilidade intestinal in vitro, utilizando segmentos jejunais de $7 \mathrm{~cm}$ obtidos de ratos Wistar (259-300 g). Para testar o modelo foi utilizado o PEG 900 radioativamente marcado. As medidas de permeabilidade intestinal in vitro foram realizadas em três períodos (15, 30 e 45 minutos), utilizando-se uma câmara de permeabilidade.

Essa técnica, comparativamente aos modelos com células Caco-2, mostrou-se mais adequada aos estudos de transporte paracelular de fármacos. A absorção de fármacos contidos em vesículas lipídicas também pode ser adequadamente observada, possibilitando verificar a influ- 
ência do muco intestinal, das concentrações de íons sódio e dos inibidores das glicoproteínas-P na absorção. Esta metodologia pode ser uma ferramenta potencial para os estudos de mecanismos e cinética de absorção de fármacos, devido ao baixo custo e à simplicidade de sua aplicação. (Rowland, Woodley, 1981; Barthe et al., 1998; Santos et al., 1999; Chen et al., 2003).

\section{Segmentos intestinais}

O método de avaliar a absorção utilizando segmentos intestinais consiste na determinação do fluxo de fármaco através de segmento intestinal animal de tamanho apropriado, isolado e contido em equipamento adequado. A permeabilidade é baseada no aparecimento do fármaco no lado seroso e desaparecimento do lado mucoso. Para avaliar a integridade da membrana é medida a resistência elétrica transepitelial antes e durante o experimento (Grass, Sweetana, 1989; Menon, Barr, 2003). O coeficiente de permeabilidade aparente é estimado utilizando a seguinte equação (Grass, Sweetana, 1989):

$$
P_{a p p}=\left(\mathrm{V} / A^{*} \mathrm{C}_{\mathrm{o}}\right)(\mathrm{dC} / \mathrm{dT})
$$

onde: $V$ é o volume da câmara receptora; $A$ é a área superficial da membrana; $\mathrm{C}_{\mathrm{o}}$ é a concentração inicial do fármaco na câmara doadora; dC/dT representa a mudança de concentração do fármaco no compartimento receptor em função do tempo.

Werle e Hoffer (2006) descreveram um experimento utilizando esta técnica, que consistiu no estudo da inibição das glicoproteínas-P (P-gps) pela glutationa, utilizando como modelo experimental um segmento de íleo de cobaio, fixado em uma câmara contendo líquidos semelhantes aos corpóreos. Os experimentos avaliaram o transporte de glutationa no sentido absortivo e secretório. Para verificar a ação das glicoproteínas-P os experimentos foram realizados com e sem a presença de terfenadina e verapamil, que são inibidores das P-gps. Os autores concluíram que a glutationa é uma ferramenta importante para inibir a atividade das P-gps no intestino.

Essa técnica é ideal para estudar a diferença na absorção de fármacos em várias regiões intestinais. Pode-se avaliar a permeabilidade utilizando tecido intestinal humano, ou tecido animal de diferentes espécies, efetuando as correções pertinentes. Como outros métodos que empregam tecidos, eles apresentam como desvantagens a falta de sangue e nervos, a restrita viabilidade dos tecidos, além da dificuldade de preparação que pode ocasionar danos morfológicos (Balimane et al., 2000; Cook, Shenoy, 2003, Menon, Barr, 2003).

\section{Células Caco-2 e Células TC-7}

As células Caco-2 são extraídas de adenocarcinoma de cólon humano. Durante sua cultura em filtros permeáveis e porosos, elas se diferenciam espontaneamente em enterócitos, formando uma membrana composta de células em monocamada aderidas por junções e apresentam como vantagem a rápida multiplicação celular (Balimane et al., 2000). O emprego de co-solventes orgânicos (metanol, etanol, propilenoglicol e polietilenoglicol) em concentrações maiores que $1-2 \%(\mathrm{v} / \mathrm{v})$ durante os estudos de permeabilidade deve ser limitado, pois comprometem a integridade dessas junções (Balimane et al., 2000). Inicialmente as células são cultivadas em meio líquido Eagle suplementado com $10 \%$ soro de feto bovino contendo $1 \%$ de antibiótico (penicilina e/ou estreptomicina) e aminoácidos. As células são cultivas à temperatura de $37^{\circ} \mathrm{C} \mathrm{com} 5 \%$ de $\mathrm{CO} 2$ e $95 \%$ de ar atmosférico (Benet et al., 2004). A preparação das células da monocamada requer um período de cultura de três semanas. Entretanto, este tempo pode ser reduzido para menos de uma semana por modificações simultâneas no material de revestimento dos filtros e no meio de crescimento. A redução no período de cultura proporciona monocamada funcional com maior produtividade, além de reduzir a contaminação por fungos/bactérias (Chong et al., 1997). Apesar destas limitações, este é o modelo mais empregado no momento e permite obter importantes informações para o estudo de novos fármacos.

Este modelo celular pode ser utilizado para predizer a absorção oral de fármacos por transporte passivo (transcelular e paracelular) em humanos (Horie et al., 2003).

Nos últimos anos houve o crescente emprego de células Caco-2 nos ensaios de permeabilidade e absorção de fármacos. Estes modelos auxiliam na pesquisa de moléculas que apresentem potencial terapêutico, pois possibilitam prever sua absorção in vivo contribuindo para triagem de moléculas previamente aos estudos pré-clínicos. O modelo pode ser utilizado pela indústria farmacêutica na descoberta de novos fármacos ou como sistema integrado a métodos de dissolução para predizer a relação dissoluçãoabsorção (Artursson, Magnusson, 1990; Rubas et al, 1993; Artursson, Borchardt, 1997; Ginsk, Polli, 1999; Lentz et al., 2000; Gershanik et al., 2000; Kobayashi et al., 2001; Neulroff et al., 2005).

Kobayashi e colaboradores (2001) avaliaram a capacidade do sistema integrado contendo células Caco-2 e métodos de dissolução em predizer a absorção de fármacos. Eles determinaram a fração de fármaco dissolvida e a fração de fármaco permeada, ambas em função do tempo, para fármacos solúveis em água como: cloridrato de ozagrel, levofloxacino, enoxacino, tartarato de metoprolol, cloridrato 
de ranitidina, cafeína anidra, cimetidina e o albendazol, que é fracamente solúvel em água. Estes estudos foram corroborados por Lentz e colaboradores (2000) para outros fámacos (atenol, manitol, furosemida, fosfato de disopiramida, maleato de clorfeniramina, aspirina, indometacina, dexametazona, cloridrato de diltiazem, teofilina e cumarina), sendo o tartarato de metoprolol empregado como referência para alta permeabilidade. Os resultados apresentados possibilitaram verificar uma coerência entre os dados de permeabilidade obtidos por meio deste método e os descritos no SCB.

Embora sejam poucas, existem limitações ao emprego de células Caco-2 para avaliar a absorção. Dentre elas pode-se citar o reduzido número de transportadores (como peptídeos: PEPT 1 e PEPT 2); a baixa permeabilidade de compostos hidrofílicos; os danos causados à membrana devido à presença de co-solventes no sistema; a aderência física do fármaco ao filtro de policarbonato, apresentando reduzida permeação e o elevado tempo de crescimento das células Caco-2 (Chong et al., 1996; Chong et al., 1997; Balimane et al., 2000).

No modelo citado anteriormente, transportadores farmaceuticamente importantes são quantitativamente inexpressivos quando comparados à absorção in vivo. Isto pode explicar o fato de que antibióticos beta-lactâmicos (cefalexina, amoxicilina) apresentam baixa permeabilidade através da monocamada de células Caco-2, mas são completamente absorvidos in vivo (Chong et al., 1996).

Compostos hidrofílicos com baixa massa molecular (ranitidina, atenolol, furosemida, hidroclorotiazida, entre outros) apresentam fraca permeabilidade (igual ou menor à do manitol) através de células Caco-2, embora em humanos a absorção seja maior que 50\% (Balimane et al., 2000).

As células TC-7 são subclones isolados das células Caco-2, sendo morfologicamente semelhantes com presença de borda em "escova", microvilosidades e formação de junções. Aparentemente mais homogêneas que as células de Caco-2, elas apresentam vantagens como menor tempo de crescimento, borda em escova mais desenvolvida e secreção de glicoproteínas-P semelhante ao epitélio intestinal (Gres et al., 1998).

Existem diferenças entre as membranas formadas por células Caco-2 e seus subclones. Um exemplo foi descrito por Bock-Hennig e colaboradores (2002), durante o estudo da regulação da expressão de UDP-glicuroniltransferases (UGT) em humanos. As UGTs no epitélio humano podem significar um sistema de desintoxicação de agentes presentes em nossa dieta. Após a quantificação desses agentes em sistemas contendo células Caco-2 ou seus subclones, os autores concluíram que é maior a expressão de UGT 1 A6 no subclone TC-7 (Bock-Hennig et al., 2002).

\section{Células 2/4/A1}

De acordo com Tavelin e colaboradores (1999), 2/4/ A1 são células originárias do intestino fetal de ratos. Estas podem mimetizar a permeabilidade do intestino delgado humano para transporte passivo (transcelular e paracelular). Estas células formam monocamadas diferenciáveis com finas junções e presença de borda em "escova".

As junções nas células de Caco-2 parecem ser mais estreitas que as junções das células endoteliais do intestino humano, o que não ocorre nas células 2/4/A1. Devido a isto, as células 2/4/A1 são consideradas adequadas ao estudo de fármacos absorvidos de forma lenta e incompleta, transportados por via paracelular, como o atenolol e a furosemida (Tavelin et al., 2003a).

As células 2/4/A1 apresentam como desvantagem alta variabilidade na sua constituição e viabilidade devido a mudanças de temperatura. Culturas a $39^{\circ} \mathrm{C}$ são bastante frágeis ocasionando, freqüentemente, morte celular. Como alternativa pode-se realizar adequado crescimento a $37^{\circ} \mathrm{C}$, porém ocorre menor diferenciação das células da monocamada com baixa expressão das enzimas presentes na borda em escova, se comparado ao cultivo a $39{ }^{\circ} \mathrm{C}$ (Tavelin et al., 2003b).

\section{Células MDCK}

MDCK é um modelo de células de rim canino ("Madin-Darby"). Estas células quando cultivadas em membranas semi-permeáveis se diferenciam em epiteliais colunares, com junções semelhantes às células Caco-2. Este modelo foi descrito inicialmente em 1989 (Cho et al., 1997) e, posteriormente, foi utilizado para avaliar a pemeabilidade in vitro de novos compostos (Irvine et al., 1991). As células MDCK foram inseridas em cultura de membranas de alta densidade e incubadas por 3 dias, representando tempo significativamente inferior ao necessário para o crescimento de células Caco-2. A permeabilidade de 55 compostos absorvidos passivamente, já descrita na literatura, foi avaliada utilizando membranas compostas por células MDCK e Caco-2. Para tal foi determinada a permeabilidade efetiva nos sentidos apical para basolateral e basolateral para apical em ambos os modelos, sendo os resultados obtidos semelhantes. Porém, como a expressão de transportadores é diferente nos tecidos intestinais e renais, também ocorre diferença entre estes modelos (Balimane et al., 2000). Ainda não são conclusivos os estudos sobre a correspondência entre estes dados de permeabilidade e os valores de absorção humana para compostos secretados ou transportados ativamente.

As células MDCK são largamente utilizadas para 
estudar a fisiologia tubular distal renal, incluindo o transporte de íons. Os íons $\mathrm{Na}^{+} \mathrm{e} \mathrm{Cl}$ - são filltrados nos rins e cerca de 5 a $10 \%$ de sua reabsorção é regulada por co-transportadores. As células MDCK representam um dos poucos modelos que expressam quantidade adequada de co-transportadores. Estes estudos são relevantes no delineamento da terapêutica com compostos diuréticos tiazídicos empregados no tratamento da hipertensão (Jong et al., 2003; Wegmann, Nüsing, 2003).

\section{SISTEMAS INTEGRADOS DISSOLUÇÃO/ ABSORÇÃO}

A resposta biológica ou terapêutica do produto farmacêutico pode estar relacionada com a quantidade e a velocidade de passagem do fármaco para a corrente sangüínea. Para fármacos contidos em formas farmacêuticas sólidas é necessário que ocorra a sua liberação da formulação, seguida da dissolução nos líquidos corpóreos e posterior permeação através das membranas biológicas (Dunne et al., 1999). Modelos in vitro que permitam simular estes processos são úteis para prever a absorção in vivo. Ginski e Polli (1999) descreveram um sistema contínuo de dissolução/permeação. O método consistiu em um estudo de dissolução utilizando os meios descritos nos compêndios farmacêuticos, com retirada de alíquotas do meio de dissolução nos tempos: 5, 10, 20,30, 40 e 60 minutos e cálculo da quantidade ou fração de fármaco dissolvido nos referidos tempos. O meio contendo o fármaco dissolvido foi bombeado para uma câmara em contato com a membrana de células Caco-2. A determinação da permeação do fármaco foi efetuada calculando-se a permeabilidade efetiva do fármaco através da membrana em meio isotônico. Para determinar a relação entre dissolução e permeação foram traçados gráficos contendo as frações dissolvidas $(F d)$ e absorvidas $(F a)$ em função do tempo. Os dados de $F$ d são obtidos diretamente quantificando a concentração em determinado tempo. Os valores de tempo associados a $F$ a devem ser ajustados, pois antes que a permeação se inicie é necessário que tenha ocorrido a dissolução. Devido a isto se calculou o tempo médio de dissolução e o valor encontrado foi somado aos tempos de permeação, que foram 20, 40, 60, 90, 120 e 180 minutos. Com este estudo foi possível conhecer previamente as frações absorvida e dissolvida de formulações, antes dos estudos clínicos em humanos. Este sistema apresenta como limitação o emprego de membranas constituídas apenas por células Caco-2 (Ginski et al., 1999).

Kobayasi e colaboradores (2001) descreveram um modelo que possibilita empregar membranas artificiais ou tecidos isolados de animais para determinar a permeação.
Este simula também as condições fisiológicas do trato gastrintestinal, ajustando o $\mathrm{pH}$ do meio a valores semelhantes ao $\mathrm{pH}$ estomacal e intestinal. O procedimento experimental consiste na colocação do fármaco em um compartimento contendo suco gástrico artificial $(\mathrm{pH} 1,0)$. Este meio contendo a fração dissolvida do fármaco é bombeado sob fluxo constante de $0,5 \mathrm{~mL} / \mathrm{min}$ para um compartimento contendo meio com $\mathrm{pH}$ ajustado para 12,0 ou 6,0 , simulando a mudança de $\mathrm{pH}$ que ocorre no TGI. Posteriormente, a solução passa para outro compartimento onde será simulada a absorção. Este será o compartimento doador que está em contato com a membrana adequada para avaliar a permeação. O fluxo é aumentado para $1,0 \mathrm{~mL} / \mathrm{min}$ e o fármaco é permeado para um compartimento receptor contendo solução com eletrólitos e pH 7,4. As amostras são coletadas em diferentes compartimentos e tempos. Os dados de fração dissolvida e fração absorvida são empregados em um modelo farmacocinético monocompartimental para o cálculo da área sob a curva de concentração plasmática do fármaco em função do tempo (Kobayashi et al., 2001; He et al., 2003).

\section{CONCLUSÃO}

Existem muitos estudos objetivando substituir os métodos in vivo destinados a determinação da absorção de fármacos por métodos in vitro. Foram observados avanços neste sentido, devido ao aprimoramento das técnicas de cultura de células e aos sistemas acoplados de dissolução e permeação. Porém, estas técnicas ainda são limitadas, requerem estudo e padronização para o cultivo das células, além de não reproduzirem adequadamente os mecanismos de transporte ativo de fármacos.

\section{ABSTRACT \\ In vitro models for the determination of drug absorption and a prediction of dissolution/absorption relationships}

Drugs contained in a solid pharmaceutical form should be adequately water soluble and permeable, into the intestine in order to be effectively absorbed after oral administration. The speed and extent at which a drug is absorbed can vary due to its physicochemical characteristics and factors related to disintegration and dissolution of the drug. According to Biopharmaceutical Drug System Classification (BSC), the dissolution and the intestinal permeation of a drug can limit the absorption and, consequently, the therapeutic action of that drug. This article focuses on data concerning the predictability of 
dissolution and absorption of drugs using in vitro models. There are several methods for determining in vitro intestinal permeability. These include diffusion studies with intestinal segments from various species or with cultured cell monolayer. Some of the most commonly used cell models are Caco-2, TC-7, 2/4/A1 and MDCK. Caco-2 cells have been the most extensively characterized and useful cell models. The Caco-2 cell, a human colon adenocarcinoma, undergoes spontaneous enterocytic differentiation in culture. A dissolution Caco-2 system has been developed to predict dissolution/absorption relationships of oral solid dosage forms of drugs prior to human studies. The in vitro permeability models represent an important tool for drug discovery within the pharmaceutical industry. However, similar models are likely to generate false negative results with actively transported drugs, and the use of a sophisticated mathematical model could be required.

UNITERMS: Drug/permeability. Drug/oral absorption. Drug/dissolution test. In vitro models. Caco-2 cell.

\section{AGRADECIMENTOS}

À Universidade de São Paulo (USP), à Universidade Federal de Ouro Preto (UFOP) e ao PICDT/CAPES.

\section{REFERÊNCIAS BIBLIOGRÁFICAS}

AMIDON, G.L.; LENNERNÄS, H.; SHAH, V.P.; CRISON,J.R.A theoretical basis for a biopharmaceutical drug classification: the correlation of in vitro drug product dissolution and in vivo bioavailability. Pharm. Res., v.12, n.3, p.413-420, 1995.

ARTURSSON, P.; BORCHARD, R.T. Intestinal drug absorption and metabolism in cell cultures: Caco-2 and beyond. Pharm. Res., v.14, n.12, p.1655-1658, 1997.

ARTURSSON, P.; MAGNUSSON, C. Epithelial transport of drug in cell culture. II: Effect of extracellular calcium concentration on paracellular transport of drugs of different lipophilicities across monolayers of intestinal epithelial (Caco-2) cells. J. Pharm. Sci., v.79, n.7, p.595600, 1990.

ASADA, H.; DOUEN, T.; WAKI, M.; ADACHI, S.; FUJITA, T.; YAMAMOTO, A.; MURANISHI, S. Absorption characteristics of chemical modified-insulin derivatives with various fatty acids in the small and large intestine. J. Pharm. Sci., v.84, p.682-687, 1995.
ATISOOK, K.; CARLSON, S.; MADARA, J.L. Effects of phlorizin and sodium on glucose-elicited alterations of cell junctions in intestinal epithelia. Am. J. Physiol., v.258, p. c77-c85, 1990.

AUNGST, B.; SHEN, D.D. Gastrointestinal absorption of toxic agents. In: ROZMAN, K.; HANNINEN, O. (Eds.), gastrointestinal toxicology. Elsevier, Amsterdam, 1986. p 29-56.

AULTON, M.E. Pharmaceutics: the science of dosage form design. New York: Churchil Livingstone, 1996. 734p.

BALAN, G.; TIMMINS, P.; GREENE, D.S.; MARATHE, P.H. In vitro-in vivo correlation (IVIVC) models for metformin after administration of modified-release (MR) oral dosage forms to healthy human volunteers. J. Pharm. Sci., v.90, p.1176-1185, 2001.

BALIMANE, P.V.; CHONG, S.; MORRISON, R.A. Current methodologies used for evaluation of intestinal permeability and absorption. J. Pharmacol. Toxicol. Methods, v.44, p. 301-312, 2000.

BANAKAR, U.V. Pharmaceutical dissolution testing. New York, Marcel Dekker, 1992.437p.

BARTHE, L.; WOODLEY, J.F.; KENWORTHY, S.; HOUIN,G. An improved everted gut sac as a simple and accurate technique measure paracellular transport across the small intestine. Eur. J. Drug Metab. Pharmacokinet., v.23, n.2, p.313-323, 1998.

BENET, L.Z.; CUMMINS, C.L.; WU, C.Y. Unmasking the dynamic interplay between efflux transporters and metabolic enzymes. Int. J. Pharm., v.277, p.3-9, 2004.

BOCK-HENNIG B.S.; KÖHLE C.; NILL K.; BOCK, K.W. Influence of $t$-buthylhydroquinone and b-naphythoflavone on formation and transport of 4-methylumbelliferone glucuronide in Caco-2/TC-7 cell monolayers. Biochem. Pharmacol., v.63, p.123-128, 2002.

BRASIL. RE n 482, de 19 de março de 2002. "Guia para estudos de correlação in vitro in vivo (CIVIV)". Via Internet, no endereço eletrônico. Disponível em http://elegis.bvs.br/leisref/public/showAct.php?id=1237\& word $=$. Acesso em 10 jun 2005. 
ÇELIK, M. The past, present, and future of tableting technology. Drug Develop. Ind. Pharm., v.22, n.1, p.1-10, 1996.

CHARMAN, W.N.; PORTER, C.J.H.; MITHANI, S.; DRESSMAN, J.B. Physicochemical and physiological mechanisms for the effects of food on drug absorption: The role of lipids and pH.J. Pharm. Sci., v.86, n.3, p.269-279, 1997.

CHATURVEDI, P.R.; DECKER, C.J.; ODINECS, A. Prediction of pharmacokinetics properties using experimental approaches during early drug discovery. Curr. Opin. Chem. Biol., v. 5, p. 452-463, 2001.

CHEN, Y; PING, Q.; GUO, J.; WENLI, L.; GAO, J. The absorption behavior of cyclosporin A lecithin vesicles in rat intestinal tissue. Int. J. Pharm., v. 261, p.21-26, 2003.

CHONG, S.; DANDO, S.; SOUCEK, K.; MORRISON, R. In vitro permeability through Caco- 2 cells is not quantitatively predictive of in vivo absorption for pe0ptide like drugs absorbed via the dipeptide transporter system. Pharm. Res., v.13, p.120-123, 1996.

CHONG, S.; DANDO, S.; MORRISON, R. Evaluation of Biocat intestinal epithelium differentiation environment (3day cultured Caco-2 cells) as na absorption screening model with improved productivity. Pharm. Res., v.14, p.1835-1837, 1997.

CONCIGLIERI, V.O.; STORPIRITIS, S. Bioequivalência de medicamentos: objetivos, parâmetros farmacocinéticos, delineamento experimental e critérios de avaliação. Rev. Bras. Cienc. Farm., São Paulo, v.36, p.13-21, 2000.

COOK, T.J.; SHENOY, S.S. Intestinal permeability of chlropyrifos using the single-pass intestinal perfusion method in the rat. Toxicol., v.184, p.125-133, 2003.

COX, D.C.; DOUGLAS, C.C.; FURMAN, W.B.; KIRCHHOEFER, R.D.; MYRICK, J.W. Guidelines for dissolution testing. Pharm. Technol., New York, v.2, p.4153, 1978.

CUTLER, D.J.; BEYSSAC, E.; AIACHE, J.M. Level B and $\mathrm{C}$ in vivo/in vitro correlations: statistical considerations. Int. J. Pharm., v.158, p.185-193, 1997.
DESESSO, J.M.; JACOBSON, C.F. Anatomical and physiological parameters affecting gastrointestinal absorption in humans and rats. Food Chem. Toxicol., v.39, p.209-228, 2001

DOKOUMETZIDIS, A.; MACHERAS, P. A century of dissolution research: from Noyes and Whitney to the biopharmaceutics classification system. Int. J. Pharm., v. 321, p. 1-11, 2006.

DRESSMAN, J.B.; AMIDON, G.L.; FLEISHER, D. Absorption potential: estimating the fraction absorbed for orally administered compounds. J. Pharm. Sci., v. 74, p. 598-599, 1985.

DRESSMAN, J.B.; AMIDON, G.L.; REPPAS, C.; SHAH, V.P. Dissolution testing as a prognostic tool for oral drug absorption: immediate release dosage forms. Pharm. Res., v. 15, n. $1,1998$.

DUNE, A.; DEVANE, J.; O'HARA, T. The relationship between in vitro drug dissolution and in vivo absorption. Statistician, v.48, p.125-133, 1999.

EDDINGTON, N.D.; MARROUM, P.; UPPOOR, R.; HUSSAIN, A.; AUGSBURGER, L. Development and internal validation of an in vitro-in vivo correlation for a hydrophilic metoprolol tartrate extended release tablet formulation. Pharm. Res., v.15, p.466-473, 1998.

FARMACOPÉIA brasileira. 4.ed. São Paulo:Atheneu, 1988. pt.1.

GALVÄO, F. H. F.; WAITZBERG, D. L.; GONÇALVES, E. L.; SOARES, A. D. C. Permeabilidade intestinal de intestino delgado de ratos, preservados hipotermicamente com as soluções da Universidade de Wisconsin e EuroCollins. Acta Cir. Bras., v. 8, p.54-8, 1993.

GERSHANIK, T.; HALTNER, E.; LEHR, C.-M.; BENITA, S. Charge-dependent interaction of self-emulsifying oil formulations with Caco-2 cells monolayers: binding, effects on barrier function and cytotoxicity. Int. J. Pharm., v. 211, p. 29-36, 2000.

GINSKI, J.M.; POLLI, J.E. Prediction of dissolutionabsorption relationships from a dissolution/ Caco-2 system. Int. J. Pharm., v. 177, p. 117-125, 1999. 
GINSKI, J.M.; TANEJA, R.; POLLI, J.E. Prediction of dissolution-absorption relationships from a continuous dissolution/Caco-2 system. AAPS Pharm. Sci., v.1, n. 3, p. 1-12, 1999.

GRASS, G; SWEETANA, S. A correlation for permeabilities of passively transported compounds in monkey and rabbit jejunum. Pharm. Res., v.6, p. 857-862, 1989.

GRES M.; JULIAN B.; BOURRIE M.; ROQUES, C.; BERGER, M.; BOULENC, X.; BERGER, Y.; FABRE, G.; Correlation between oral drug absorption in human, and apparent drug permeability in TC-7cells, a human epithelial intestinal cell line: comparison with the parenteral Caco-2 cell line. Pharm. Res., v. 15, p. 726$733,1998$.

GRUNDY, J.S.; ANDERSON, K.E.; ROGERS, J.A.; FOSTER, R.T. Studies on dissolution testing of the nifedipine gastrointestinal therapeutic system. I. description of a two phase in vitro dissolution test. $J$. Control. Release, v. 48, p. 1-8, 1997.

GUIDANCE for industry: waiver of in vivo bioavailability and bioequivalence studies for immediate-release solid oral dosage forms based on biopharmaceutics classification system. Rockville: FDA. 2000. 13p.

HE, X.; SUGAWARA, M.; KOBAYASHI, M.; TAKEKUMA, Y.; MIYAZAKI, K. Na in vitro system for prediction of oral absorption of relatively water-soluble drugs and ester prodrugs. Int. J. Pharm., v. 263, p. 35-44, 2003.

HITZ, J. The absorption window: fact or fiction? Pharm. Int., p. 175-178, 1984.

HOSSAIN, M.; ABRAMOWITZ, W.; WATROUS, B.J.; SZPUNAR, G.J.; AYREES, J.W. Gastrointestinal transit of nondisintegration, nonerodible oral dosage forms in pigs. Pharm. Res., v. 7, p. 1163-1166, 1990.

HORIE, K.; TANG, F.; BORCHARDT, R.T. Isolation and characterization of Caco-2 subclones expressing high levels of multidrug resistance protein efflux transporter. Pharm. Res., v.20, p. 161-167, 2003.

IRVINE, J.D.; TAKAHASHI, L.; LOCKHART, K.; CHEONG, J.; TOLAN, J.W.; SELICK, H.E.; GROVE, J.R. MDCK (Madin-Darby canine kidney) cells: a tool for membrane permeability screening. J. Pharm. Sci., v. 88, p. 28-33, 1999.
JONG, J.C.; WILLEMS, P.H.G.M.; HEUVEL, L.P.W.J.V.D.; KNOERS, N.V.A.M.; BINDELS, R.J.M. Function expression of the human thiazide-sensitive $\mathrm{NaCl}$ cotransporter in Madin-Darby Canine Kidney Cells. $J$. Am. Soc. Nephrol., v. 14, p. 2428-2435, 2003.

KARASOV, W.H.; DARKEN, B.W.; BOTTUM, M.C. Dietary regulation of intestinal ascorbate uptake in guinea pigs. Am. J. Physiol., v. 260, p. G108-G118, 1991.

KASSIN, N.A.; WHITEHOUSE, M.; RAMACHANDRAN, C.; BERMEJO, M.; LENNERNAS, H.; HUSSAIN, A.S.; JUNGINGER, H.E; STAVICHANSKY, S.A.; MIDHA, K.K.; SHAH, V.P.; AMIDON, G.L. Molecular properties of WHO essential drugs and provisional biopharmaceutical classification. Mol. Pharm., v. 1, p. 85-96, 2003.

KATSURA, T.; INUI, K. Intestinal absorption of drug mediated by drug transporters: mechanisms and regulation. Drug Metab. Pharmacokin., v.18, n.1, p. 1-15, 2003 .

KATORI, N.; AOYAGI, N.; TERAO, T. Estimation of agitation intensity in the GI tact in humans and dogs based on in vitro/in vivo correlation. Pharm. Res., v. 12, n. 2, p. 237-243, 1995.

KHAN, M.Z.I. dissolution testing for sustained or controlled release oral dosage forms and correlation with in vivo data: challenges and opportunities. Int. J. Pharm., v. 140, p. 131-143, 1996.

KOBAYASHI, M.; SADA, N.; SUGAWARA, M.; ISEKI, K.; MIYAZAKI, K. Development of a new system for prediction of drug absorption that takes into account drug dissolution and $\mathrm{pH}$ change in the gastro-intestinal tract. Int. J. Pharm., v. 221, p. 87-94, 2001.

LABOISSE, C.L.; JARRY, A.; BOU-HANNA, C.; MELIN, D.; VALLETTE, G. Intestinal cell culture models. Eur. J. Pharm. Sci., v. 2, p. 32-38, 1994.

LENTZ, K.A.; HAYASHI, J.; LUCISANO, L.J.; POLLI, J.E. Development of a more rapid, reduced serum culture system for Caco-2 monolayers and a application to the biopharmaceutics classification system. Int. J. Pharm., v. 200, p. 41-51, 2000. 
LUO, F.R.; PARANJPE, P.V.; GUO, A.; RUBIN, E.; SINKO, P. transport of irinotecan in Caco-2 cells and MDCK II cells over expressing efflux transporters Pgp, cMOAT, and MRP1.Drug Metab. Dispos., v. 30, p. 763-70, 2002.

MACHERAS, P.; ARGYRAKIS, P. Gastrointestinal drug absorption: is it time to consider heterogeneity as well as homogeneity? Pharm. Res., v. 14, p. 842-847, 1997.

MAKHEY, V.D.; GUO, A.; NORRIS D.A.; H.U. P.; YAN, J., SINKO, P.J. Characterization of the regional intestinal kinetics of drug efflux in rat and human intestine and in Caco-2 cells. Pharm Res., v. 15, p.1160-7, 1998.

MANADAS, R.; PINA, M.E.; VEIGA, F. A dissolução in vitro na previsão da absorção oral de fármacos em formas farmacêuticas de liberação modificada. Brazilian $J$. Pharm. Sci., v. 38, p. 375-400, 2002.

MARIAPPAN T.T.; SINGH S. Evidence of efflux-mediated and saturable absorption of rifampicin in rat intestine using the ligated loop and everted gut sac techniques. Mol Pharm., v.1, p.363-7, 2004.

MARQUES, M.R.C. Desenvolvimento e validação de métodos de dissolução para formas farmacêuticas sólidas orais. Rev. Analytica, n.1, p. 48-51, 2002.

MENON, R.M.; BARR, W.H. Comparison of ceftibuten transport across Caco-2 cells and rat jejunum mounted on modified Using chambers. Biopharm. Drug Dispos., v. 24, p. 299-308, 2003.

NEULROFF, S.; UNGELL, A.L.; ZAMORA, I.; ARTUSSON, P. Ph-dependent passive and active transport of acidic drugs across Caco- 2 cell monolayers. Eur. J. Pharm. Sci., v. 25, p. 211-220, 2005.

PAPPENHEIMER, J.R.; REISS, K.Z. 1987. Contribution of solvent drag through intercellular junctions to absorption of nutrients by the small intestine of the rat. J. Memb. Biol., v. 100, p. 123-136, 1987.

PIETZONKA, P.; WALTER, E.; DUDA-JOHNER, S.; LANGGUTH, P.; MERKLE, H.P. Compromised integrity of excised porcine intestinal epithelium obtained from the abattoir effects the outcome of in vitro particle uptake studies. Eur. J. Pharm. Sci., v. 15, p. 39-47, 2002.
POLLI, J.E.; CRISON, J.R.; AMIDON, G.L. Novel approach to the analysis of in vitro-in vivo relationships. J. Pharm. Sci., v. 85, p. 753-761, 1996.

PUTNAM, W.S.; PAN, L.; TSUTSUI, K.; TAKAHASHI, L.; BENET, L.Z. Comparison of bidirectional cephalexin transport across MDCK and Caco- 2 cell monolayers: Interactions with peptide transporters. Pharm. Res., v.19, p. 27-33, 2002

RAO, B.S.; SESHASAYANA, A., SARADHI, S.V.P.; KUMAR, N.R.; NARAYAN, C.P.S.; MURTHY, K.V.R. Correlation of "in vitro" release and "in vivo" absorption characteristics of rifampicin from ethylcellulose coated nonpareil beads. Int. J. Pharm., v. 230, p. 1-9, 2001.

ROUGE, N.; BURI, P.; DOELKER, E. Drug absorption sites in the gastrintestinal tract and dosage forms for sitespecific delivery. Int. J. Pharm., v. 136, p. 117-139, 1996.

ROWLAND, R.N. ; WOODLEY, J.F. The uptake of distearoylphosphatidylcholine/cholesterol liposomes by rat intestinal sac in vitro. Biochim. Biophys. Acta, v. 673, p. 217-223, 1981.

RUBAS, W.; JEZYK, N.; GRASS, G.M. Comparison of the permeability characteristics of a human colonic epithelial (Caco-2) cell line to colon of rabbit, monkey, and dog intestine and human drug absorption. Pharm. Res., v. 10, p. 113-118, 1993.

SANTOS, C.A.; JACOB, J.S.; HETZOG, B.A.; FREEDMAN, B.D.; PRESS, D.L.; HARNPICHARNCHAI, P.; MATHIOWITZ, E. Correlation of two bioadhesion assays: The everted sac technique and the CAHN microbalance. J. Control. Rel., v. 61, p. 113-122, 1999.

SATHE, P.M.; TSONG, Y.; SHAH, V.P. In-vitro dissolution profile comparison: Statistic and analysis, model dependent approach. Pharm. Res., v. 13, p. 1799-1803, 1996.

SATO, K.; SUGIBAYASHI, K.; MORIMOTO, Y. Species differences in percutaneous adsorption of nicorandil. $J$. Pharm. Sci., v.80, p. 104-107, 1991.

SKELLY, J.P.; AMIDON, G.L.; BARR, W.H.; BENET, L.Z.; CARTER, J.E.; ROBINSON, J.R.; SHAH, V.P.; YACOBI, A. In vitro and in vivo testing and correlation for oral controlled/modified-release dosage forms. Pharm. Res., v. 7, p. 975-982, 1990. 
STORPIRTIS, S.; CONSIGLIERI, O.V. Biodisponibilidade e bioequivalência de medicamentos: Aspectos fundamentais para o planejamento e execução de estudos. Rev. Bras. Cienc. Farm., v. 31, p. 63-70, 1995.

TAVELIN S.; MILOVIC V.; OCKLIND G.; OLSSON S.; ARTURSSON P. A conditionally immortalized epithelial cell line for studies of intestinal drug transport. $J$. Pharmacol. Exper. Ther, v. 290, p. 1212-1221, 1998.

TAVELIN S.; TAIPALENSUU, J.; SÖDERBERG, L.; MORRISON, R.; CHONG, S.; ARTURSSON P. Prediction of the oral absorption of low-permeability drugs using small intestine-like 2/4/A1 cell monolayers. Pharm. Res., v. 20, p. 397-405, 2003a.

TAVELIN, S.; TAIPALENSUU, J.; HALLBÖÖK, F.; VELLONEN, K-S.; MOORE, V.; ARTURSSON P. Na improved cell culture model based on 2/4/A1 cell monolayers for studies of intestinal drug transport: characterization of transport routes. Pharm. Res., v. 20, p. 373-381, 2003b.
UNITED States Pharmacopeia: USP 29: The National Formulary: NF 24. Rockville: United States Pharmacopeial Convention, 2005. p.1064-1065, 19611963.

UPPOOR, V.R.S. Regulatory perspectives on in vitro (dissolution)/in vivo (bioavailability) correlations. $J$. Control. Rel., v. 72, p. 127-132, 2001.

WEGMANN, M.; NÜSING, R.M. Prostaglandin E2 stimulates sodium reabsorption in MDCK C7 cells, a renal collection duct principal cell model. Prostaglandins, Leukot. Essent. Fat. Acids, v. 69, p. 315-322, 2003.

WERLE M; HOFFER M. Glutathione and thiolated chitosan inhibit multidrug resistance $\mathrm{P}$-glycoprotein activity in excised small intestine. J. Control. Release., v. 111, p. 416, 2006.

Recebido para publicação em 03 de outubro de 2005. Aceito para publicação em 22 de novembro de 2007. 